\title{
A FORMAÇÃO DE AGENTES COMUNITÁRIOS DE SAÚDE: CONSTRUÇÃO A PARTIR DO ENCONTRO DOS SUJEITOS
}

\author{
THE TRAINING OF COMMUNITY HEALTH AGENTS AND \\ CONSTRUCTION FROM THE MEETING OF THE SUBJECTS
}

LA FORMACIÓN DE LOS AGENTES DE SALUD: CONSTRUCCIÓN

A PARTIR DEL ENCUENTRO DE LOS SUJETOS

\author{
Jamilly Gusmão Coelho ${ }^{1}$ \\ Luiz Carlos Fadel de Vasconcellos ${ }^{2}$ \\ Elizabeth Costa Dias ${ }^{3}$
}

Resumo Este artigo apresenta uma síntese de observações desenvolvidas em uma pesquisa que teve como objetivo elaborar um projeto pedagógico para qualificação dos agentes comunitários de saúde em vigilância em saúde do trabalhador com base na percepção dos próprios sujeitos. Tratou-se de estudo de natureza qualitativa realizado em 2016, em Vitória da Conquista, Bahia, que utilizou o referencial teórico da pesquisa-ação e a técnica de grupo focal para abordagem dos sujeitos. A primeira etapa dos resultados expõe a visão dos enfermeiros quanto à qualificação dos agentes em vigilância em saúde do trabalhador, e a segunda descreve a participação e a percepção dos agentes comunitários de saúde na construção da proposta pedagógica de capacitação. Os enfermeiros recomendaram que a capacitação em vigilância em saúde do trabalhador fosse construída com base nos pressupostos da educação permanente e demonstraram interesse em participar desse processo educativo. Houve unanimidade dos agentes participantes quanto à necessidade da capacitação. Eles sugeriram conteúdos, metodologia e material didático para a construção da proposta pedagógica, externando o desejo de participar de um processo educativo capaz de transpor as barreiras da capacitação, como um verdadeiro processo de educação permanente em saúde.

Palavras-chave vigilância em saúde do trabalhador; agente comunitário de saúde; educação permanente em saúde.
Abstract This article presents a synthesis of observations developed in a research that had as objective to elaborate a pedagogical project to qualify the community health agents in health surveillance of the worker based on the perception of the subjects themselves. It was a qualitative study carried out in 2016, in Vitória da Conquista, Bahia, Brazil, which used the theoretical reference of action research and the focus group technique to approach the subjects. The first stage of the results exposes the view of the nurses regarding the qualification of the agents in health surveillance of the worker, and the second describes the participation and the perception of the community health agents in the construction of the pedagogical proposal of training. The nurses recommended that the training in health surveillance of the worker be built based on the assumptions of permanent education and showed interest in participating in this educational process. There was unanimity of the participating agents regarding the need for training. They suggested contents, methodology and didactic material for the construction of the pedagogical proposal, expressing the desire to participate in an educational process able to overcome the barriers of training, as a true process of permanent education in health.

Keywords worker's health surveillance; community health agent; continuing health education. 


\section{Introdução}

A prática da educação permanente em saúde (EPS) apresenta-se como um desafio no cotidiano de trabalho dos profissionais na Estratégia Saúde da Família (ESF), em especial dos agentes comunitários de saúde (ACSs), que tiveram seu papel ampliado após a implantação da ESF. Contudo, o processo de qualificação desses profissionais permanece desestruturado, fragmentado e, na maioria das vezes, insuficiente para desenvolver as competências necessárias para o adequado desempenho de seu papel. Nesse sentido, a EPS da equipe multiprofissional da atenção básica (AB), em especial dos ACSs, é fundamental para que os profissionais possam atender às necessidades das famílias, direcionando o olhar e as ações de saúde para além das práticas curativas, de modo a incorporar outros saberes que os habilitem nesse processo de interação cotidiana com as famílias (Gomes et al., 2010).

Dentre os profissionais que atuam na ESF, o ACS se apresenta como um mediador entre a população e o serviço de saúde, por meio de ações educativas, prevenção de agravos e de promoção e vigilância da saúde e como agente social, no sentido de organização da comunidade e de transformação de suas condições de vida. Ele desempenha papel essencial na atenção integral à saúde dos trabalhadores, podendo realizar o cadastro e o levantamento de informações sobre o perfil ocupacional dos moradores do território, a identificação do perfil produtivo e possíveis fatores de risco relacionados às atividades produtivas.

Como membro da equipe e morador do território em que trabalha, o ACS possui amplo conhecimento sobre os processos produtivos instalados e a influência destes sobre a saúde das pessoas e também sobre o ambiente. $\mathrm{O}$ agente conhece o perfil ocupacional das famílias e geralmente estabelece, de modo intuitivo, correlação entre as principais queixas, demandas e problemas com o trabalho que desenvolve (Dias e Silva, 2013). Por conta disso, o desempenho do cuidado à saúde dos trabalhadores requer dos ACSs múltiplos saberes e habilidades, o que pressupõe a necessidade de formação sólida e permanente desses trabalhadores, com foco na atuação em equipe. Essas exigências quanto ao desempenho ganham relevância no cenário das mudanças, na forma de organização do trabalho e nas relações de produção, que têm resultado no aumento do trabalho informal, familiar e em domicílio (Dias, Rigotto e Augusto, 2009).

Nesse contexto, insere-se a necessidade e o desafio de preparar os ACSs para o desenvolvimento de ações de vigilância em saúde do trabalhador (Visat) no sentido de identificar processos produtivos geradores de riscos para a saúde, identificar o perfil ocupacional, realizar orientações e ações educativas, por exemplo, utilizando essas informações para o planejamento de ações de cuidado aos trabalhadores pela equipe.

Para Vasconcellos, Almeida e Guedes (2010), os processos de Visat são cenários pedagógicos adequados para as iniciativas de mudança das relações saúde- 
trabalho ampliadas, especialmente porque se permite abordar, simultaneamente, os dois eixos de educação do Sistema Único de Saúde (SUS) - o da educação popular e o da educação permanente.

De acordo com Ceccim e Ferla (2006), a EPS não é só um processo didáticopedagógico; é um processo político-pedagógico que trata de mudar o cotidiano do trabalho na saúde e de colocar o cotidiano profissional em invenção viva, em equipe e com os usuários. Ela se apoia no conceito de ensino problematizador e de aprendizagem significativa, isto é, ensino-aprendizagem embasado na produção de conhecimentos que respondam a perguntas que pertencem ao universo de experiências e vivências de quem aprende e que gerem novas perguntas sobre o ser e o atuar no mundo.

Desse modo, em decorrência de se estar buscando um caminho pedagógico para a qualificação dos ACSs em vigilância à saúde do trabalhador, o estudo aqui apresentado teve como objetivo a construção de uma proposta pedagógica com base na percepção dos enfermeiros das equipes de saúde da família e dos agentes comunitários de saúde. A construção da proposta pedagógica está em consonância com a Política de Educação Permanente em Saúde (PNEPS) do SUS e com a Política Nacional de Saúde do Trabalhador e da Trabalhadora (PNST) vigentes, que valorizam a qualificação dos trabalhadores da saúde mediante sua inserção no processo de trabalho, quando este passa a ser um lócus de efetivação de uma educação libertadora e produtora de autonomia em saúde. Dessa forma, os profissionais de saúde devem se sentir sujeitos de seu próprio processo educativo (Brasil, 2004, 2012).

\section{Vigilância em saúde do trabalhador na atenção básica e o papel do ACS}

A vigilância em saúde é, atualmente, um dos grandes desafios para o SUS e para a $\mathrm{AB}$, devendo ser feita de modo articulado com as vigilâncias epidemiológica, sanitária, ambiental e da saúde do trabalhador (Brasil, 2009). Diferente da vigilância em saúde, o objeto de investigação e intervenção da Visat é fruto da relação entre o processo de trabalho e a saúde. Suas ações buscam a articulação sanitária no sentido da promoção, da proteção e da atenção à saúde dos trabalhadores, direcionadas aos fatores de risco, condições e organização do trabalho, vigilância sobre danos ou efeitos e seus determinantes tecnológicos e sociais (Machado, 2013).

Contudo, ainda que o SUS não esteja preparado para enfrentar muitas questões relacionadas ao processo trabalho-saúde-doença, o que se observa é que os danos à saúde gerados pelos processos produtivos desenvolvidos no território de atuação da $\mathrm{AB}$ muitas vezes se apresentam às equipes e, em especial aos ACSs, que se veem diante da necessidade de oferecer à população 
algum tipo de solução. Dessa forma, não se trata de introduzir uma nova ação na $\mathrm{AB}$, e sim de requalificar e ampliar as que já existem de forma integrada com a vigilância em saúde (Dias, Silva e Almeida, 2012).

Para essas autoras, embora haja questionamentos quanto à classificação de algumas ações desenvolvidas na $\mathrm{AB}$ como sendo 'de vigilância', por não cumprirem um ciclo completo e não incluírem a intervenção sobre os ambientes e condições de trabalho, é importante reconhecer que tais ações cumprem a tarefa inicial e essencial de identificar situações-problema, muitas vezes complexas, que podem ser ampliadas caso sejam dadas condições e suporte a essas equipes. Entretanto, a intervenção sobre essas situações-problema muitas vezes requer a atuação integrada com outros setores, como o Centro de Referência em Saúde do Trabalhador (Cerest), ${ }^{4}$ a vigilância sanitária e ambiental, as superintendências regionais do trabalho.

As mudanças ocorridas no contexto do trabalho ao longo dos anos, mediadas pelas novas tecnologias e formas de gestão dos processos produtivos, desencadearam novos padrões de comportamento e modos de viver. Como consequências desse processo surgem, entre outras consequências, o desemprego estrutural, o aumento da complexidade das tarefas, a precarização dos vínculos e a ausência ou fragilidade da proteção social dos trabalhadores (Dias, Rigotto e Augusto, 2009). Observa-se a transferência de atividades produtivas para as residências dos trabalhadores, resultando no fenômeno do trabalho em domicílio. Com frequência, o trabalho domiciliado degradado é desenvolvido em ambientes adaptados, por trabalhadores mais vulneráveis, desprotegidos e sem treinamento adequado, o que representa risco para a saúde deles e de seus familiares (Vieira, 2009).

Diante de tal panorama, muitas vezes o Estado só alcança esses trabalhadores por meio das ações do SUS, especialmente da atenção básica, o que contribui para reforçar a importância e o papel da $\mathrm{AB}$ para o cuidado de saúde da população trabalhadora que, de modo particular, adoece e morre em razão das atividades de trabalho que desenvolve (Dias e Silva, 2013).

Estudo desenvolvido por Silva, Dias e Ribeiro (2011) sobre as práticas do ACS com relação às ações de saúde do trabalhador revelou que as ações desenvolvidas por esses profissionais em seu território de abrangência podem ser caracterizadas como pontuais e pouco institucionalizadas, dependendo, em grande parte, de iniciativas pessoais. As autoras concluíram que raramente o ACS foi capacitado para lidar com as questões relacionadas ao processo trabalho-saúde-doença, o que o faz orientar a solução dos problemas de acordo com o senso comum ou experiências anteriores similares. Tal fato reforça a necessidade de os processos de capacitação e educação permanente dos ACSs incorporarem essas questões, possibilitado o desenvolvimento de ações resolutivas no cuidado à saúde dos trabalhadores. 
No contexto da Visat na atenção básica, algumas características da $\mathrm{AB}$ podem facilitar o desenvolvimento dessas ações: a organização territorial; os vínculos entre a população e a equipe de saúde, mediados pelo ACS; a possibilidade de atenção contínua e integral; a atuação multiprofissional e a presença do ACS, que representa um diferencial no trabalho da equipe de saúde (Dias, Silva e Almeida, 2012).

Diante do exposto, para abordar as questões de Visat no contexto da AB, é necessária uma articulação de ações intra e intersetoriais de processos consistentes de EPS. Para Dias e Silva (2013), é fundamental garantir o suporte técnico e pedagógico para as equipes a fim de que elas possam planejar suas atividades considerando os usuários trabalhadores que integram a população do território de abrangência da equipe.

Nesse cenário, o Cerest, criado em 2002, é compreendido como polo irradiador da relação entre processo de trabalho e saúde. Deve assumir a função de suporte técnico e científico em saúde do trabalhador, ao lado de difundir informação para ações de vigilância, facilitando a educação permanente para profissionais e técnicos do SUS e controle social. Assim, o Cerest se vê diante da oportunidade de redefinir seu papel, atuando como núcleo de inteligência e centro articulador das ações intra e intersetoriais e de apoio técnico e especializado para o desenvolvimento de ações de Saúde do Trabalhador (ST) na rede de atenção à saúde, conforme descrito pela PNST. É com esse sentido que o Cerest assume o apoio matricial para o desenvolvimento de ações de ST na $A B$, nos serviços especializados e de urgência e emergência e em outras instâncias de promoção e vigilância (Dias e Hoefel, 2005).

De acordo com Silva e Dias (2013), a análise da situação de saúde dos territórios de atuação das equipes de Saúde da Família (eSF) é considerada fundamental para a organização da produção do cuidado aos trabalhadores na $A B$ e deve ser discutida com a equipe de apoio matricial em ST. As autoras ressaltam que atividades como a definição do perfil produtivo; a identificação de situações de vulnerabilidade e riscos à saúde da população; o levantamento de informações sobre as principais queixas e problemas de saúde dos trabalhadores que residem na área de atuação das equipes da $A B$; e a eleição de 'casos' ou situações prioritárias para a intervenção devem ser apoiadas e matriciadas por profissionais da equipe do Cerest, da Visat ou da vigilância ambiental.

O apoiador matricial deve auxiliar na qualificação dos ACSs para o mapeamento e o registro das atividades produtivas e a sistematização dos dados coletados, de forma a definir o perfil das atividades produtivas domiciliadas. A escolha dos processos e ambientes de trabalho em domicílio, objeto das ações de intervenção, deve considerar as atividades produtivas mais comuns no território; o potencial de dano à saúde dos trabalhadores e de seus familiares; as situações de vulnerabilidade e demanda dos próprios trabalhado- 
res. No processo de qualificação, as visitas aos domicílios devem ser feitas de forma conjunta com o apoiador. A contribuição dos ACSs é fundamental para facilitar o diálogo entre usuários e profissionais de saúde e diminuir as resistências, pois muitas vezes essas atividades são exercidas à margem dos regulamentos municipais ou estaduais.

Para Silva, Dias e Ribeiro (2011), são atribuições dos ACSs no cuidado à saúde dos trabalhadores: identificar o lugar em que as pessoas trabalham e as situações de trabalho de todos os membros da família; mapear atividades produtivas no espaço domiciliar e no entorno, apontando possíveis riscos aos quais pode estar exposto o trabalhador ou a família; orientar o trabalhador sobre os riscos a sua saúde e sobre a garantia de direitos previdenciários, trabalhistas e sociais; registrar dados sobre doenças e agravos relacionados ao trabalho e repassar à equipe; identificar e reconhecer atividades produtivas do território, dentre outras ações.

\section{EPS: um caminho para liberdade, autonomia e cidadania dos sujeitos}

A PNEPS, implantada pelo Ministério da Saúde por meio da portaria GM/ MS n. 198/2004 e reformulada pela portaria GM/MS n. 1.996/2007, considera a EPS como uma proposta educativa que está destinada à aprendizagem no trabalho, em que o aprender e o ensinar se incorporam ao cotidiano das organizações e ao trabalho. Esta proposta pode ser entendida como aprendizagem-trabalho, pois, parte do cotidiano das pessoas e das organizações, dos problemas enfrentados na realidade e dos conhecimentos e experiências dos sujeitos (Brasil, 2004, 2007). Nessa linha, a EPS é um conceito de processo educativo considerado como uma síntese operativa da "educação no trabalho, pelo trabalho e para o trabalho" (Rovere, 1993; Quintana, Roschke e Ribeiro, 1994, p.54).

Ceccim e Ferla (2006) consideram que a EPS configura-se, ao mesmo tempo, como uma prática de ensino-aprendizagem e uma política de educação na saúde. Como prática de ensino-aprendizagem, ela se apropria da realidade vivenciada no cotidiano do trabalho em saúde e dos problemas e experiências dos atores envolvidos, a partir dos quais se produzem conhecimentos que geram mudança. Como política de educação na saúde, a EPS tem contribuído para a construção do SUS.

O Ministério da Saúde define que

a educação permanente parte do pressuposto da aprendizagem significativa (que promove e produz sentidos) e propõe que a transformação das práticas profissionais deva estar baseada na reflexão crítica sobre as práticas reais de profissionais reais em ação na rede de serviços (Brasil, 2004, p. 37). 
Assim, a EPS está articulada às diretrizes e aos princípios do SUS que, por sua vez, têm na ESF uma de suas mediações para se concretizar. Para atuar no SUS, a Educação Permanente em Saúde interpõe, nesta vertente, a reflexão crítica sobre as práticas assistenciais e de gestão (Brasil, 2004).

A possibilidade de uma educação para a saúde que considere o sentido que cada um dá à sua vida, como a controla, convivendo solidariamente em comunidade, a partir da retomada das experiências de cada envolvido no processo educativo, é um caminho para a liberdade e para a construção de autonomia.

Uma educação popular ou libertadora, de acordo com Paulo Freire, “não pode fundar-se numa compreensão dos homens como seres vazios a quem o mundo encha de conteúdos (...), mas nos homens como corpos conscientes e na consciência intencionada ao mundo" (Freire, 2014, p. 77). Essa educação é diferente da educação bancária, depositária, na qual se transmite conhecimento e se coloca, de um lado, o educador e, de outro, o educando.

Freire enfatiza a necessidade de respeito ao conhecimento que o educando traz consigo, visto ser ele um sujeito social e histórico, e da compreensão de que "formar é muito mais do que puramente treinar o educando no desempenho de destrezas" (Freire, 2013, p. 15). Compreender a existência do ser humano como um ser social e histórico é indispensável para o campo da saúde.

A divisão da responsabilidade pela saúde entre profissional e usuário é um ato de coragem e, mais do que isso, a valorização dos sujeitos no processo de construção e manutenção da sua própria saúde. Paulo Freire (2007) deixa claro o que pensa sobre o processo educativo sugerido para a área da saúde: uma educação em saúde problematizadora e emancipatória para todos os envolvidos no processo.

Várias estratégias e orientações são propostas para a implementação de processos de EPS. Em princípio, a mudança de foco de trabalhadores na condição de recursos para trabalhadores como protagonistas do processo educativo é condição fundamental e indispensável. Rovere (1993) afirma que o ponto de partida para um trabalho de educação permanente é a redefinição das tarefas dos sujeitos mediante questionamentos a si próprios.

De acordo com esse mesmo entendimento, para que o sujeito seja ator da construção do seu processo educativo, ele deve ser compreendido como sujeito sanitário na perspectiva do direito - que, de acordo com Vasconcellos e Oliveira (2013), se expressa na agregação de valores e significados simbólicos que traduzem suas características e suas credenciais para que possa ser, assim, ele mesmo protagonista, considerado nas políticas públicas de saúde, neste caso, na Política de Educação Permanente em Saúde. Portanto, ser sujeito sanitário significa ser sujeito construtor de sua própria cidadania no âmbito da saúde pública, portanto, portador de uma cidadania sanitária. 
Para que a EPS seja compreendida em sua totalidade, requer que seus atores se percebam como sujeitos sanitários e se sintam convocados à criação, à abertura, ao coletivo. O investimento pedagógico, para quebrar o que está posto, precisa ampliar as noções de autonomia do outro e constituir espaços criativos e sensíveis na produção da saúde, oportunizando ao sujeito sanitário opinar, contribuir na construção do seu próprio processo de formação e participar dele.

Nesse espaço educativo, formativo, informativo e de ebulição de uma autonomia do sujeito, todos participam de um novo processo pedagógico de construção da política. Agente formador, profissional de saúde e o próprio usuário do sistema se imbricam numa dinâmica transformadora do aprender para mudar para, em seguida, mudar para aprender e assim sucessivamente. É, em essência, um grande encontro dos sujeitos que compõem a estrutura humana do sistema de saúde, consolidados no objetivo comum de, construindo uma cidadania sanitária, construir o próprio SUS.

\section{Os sujeitos e a construção do processo pedagógico}

Este artigo apresenta uma síntese de observações desenvolvidas no estudo de Coelho (2016), que teve como objetivo elaborar um projeto pedagógico para qualificação dos ACSs em Visat com base na percepção dos próprios sujeitos. A pesquisa foi realizada no município de Vitória da Conquista, Bahia, com abordagem qualitativa, ancorada no referencial teórico da pesquisaação no período de 2015 a 2016 (Thiollent, 2011). Os dados foram analisados segundo a técnica de análise de conteúdo (Bardin, 2011).

A base teórica se compôs da revisão bibliográfica da produção técnicocientífica nas bases de dados do Scientific Electronic Library Online (SciELO) e Literatura Latino-Americana e do Caribe em Ciências da Saúde (Lilacs), a partir dos descritores: saúde do trabalhador, atenção básica, vigilância em saúde do trabalhador, agentes comunitários de saúde e educação permanente em saúde. Utilizou-se também o tema-chave perfil e formação dos agentes comunitários de saúde. Definiu-se o período de busca como sendo de 2006 a 2014. O campo do estudo foi caracterizado com base em dados sociodemográficos, socioeconômicos, epidemiológicos e perfil produtivo do município.

Os sujeitos da pesquisa foram os enfermeiros e os ACSs das equipes de saúde da família (eSF). Os enfermeiros foram escolhidos por serem historicamente responsáveis pela capacitação e pelo acompanhamento das ações dos agentes comunitários de saúde, por assumirem a atribuição de supervisão do trabalho dos ACSs, conforme determina a Política Nacional da Atenção Básica (Brasil, 2011), e serem considerados elementos indispensáveis para a concretização das ações de Visat na AB. Como o município possui $42 \mathrm{eSF}$, foram convidados os 42 enfermeiros dessas equipes. Entretanto, participaram da pesquisa 35 profissionais. 
Para seleção dos ACSs como sujeitos da pesquisa, consideraram-se como critério de inclusão para participação no estudo 50\% das unidades de zona urbana e 50\% das unidades de zona rural. Foram sorteadas 12 (50\%) unidades de saúde urbanas e oito (50\%) unidades de saúde rurais. Convidou-se um ACS de cada unidade selecionada, adotando-se como critério de escolha o agente com maior tempo de trabalho. Para enriquecer a discussão do grupo focal (técnica de pesquisa utilizada com os ACSs), incluiu-se no estudo a equipe de saúde da família de Lagoa das Flores, considerada como zona intermediária entre urbana e rural. A divisão em zonas urbana e rural foi utilizada para definir os grupos focais tendo em vista que as regiões podem apresentar demandas distintas para as ações em ST, já que as atividades produtivas e as condições de trabalho podem se organizar de modos diferentes.

A pesquisa de campo deu-se por meio de questionário semiestruturado aplicado aos enfermeiros e técnica de grupo focal utilizada para abordagem dos ACSs. Foi aprovada pelo Comitê de Ética em Pesquisa da Escola Nacional de Saúde Pública Sergio Arouca, Certificado de Apresentação para Apreciação Ética n. 43969115.5.0000.5240, em 30 de maio de 2015. Não contou com financiamento de instituição pública ou privada, e não existiram conflitos de interesse.

\section{Os enfermeiros e a qualificação dos ACSs em Visat}

Participaram dessa etapa 35 enfermeiros. Destes, 25 trabalhavam em unidades de saúde da zona urbana e dez na zona rural. Dos entrevistados, $89 \%$ eram do sexo feminino, predominância observada em todo o contexto da profissão de enfermagem; $37 \%$ apresentaram tempo de formação correspondente a dez anos ou mais; e $26 \%$, quatro a seis anos de formados, o que demonstra que o quadro de enfermeiros do município é bem misto. Chamou a atenção o pouco tempo de trabalho na atenção básica do município de Vitória da Conquista - 40\% dos enfermeiros informaram de um a dois anos (período de realização do último concurso público municipal). Com relação à variável capacitação, $63 \%$ dos enfermeiros nunca foram capacitados para ações voltadas à saúde do trabalhador - o que, de certa forma, pode significar um entrave no apoio à qualificação do ACS em Visat, haja vista que os enfermeiros são responsáveis pela supervisão do trabalho e também pelas capacitações para os agentes. Esse fato também aponta para uma necessidade de capacitação em Visat para os enfermeiros.

A análise dos dados dessa etapa permite afirmar que os enfermeiros reconheciam como atribuição da $\mathrm{AB}$ o desenvolvimento de ações de ST; no entanto, eles não desenvolviam essas ações em sua rotina de trabalho na mesma proporção. 
Os ACSs são essenciais para o estabelecimento de vínculo e relações de confiança entre a comunidade e a equipe de saúde, pois desempenham um papel fundamental na atenção integral à saúde dos trabalhadores, ao cadastrar e recolher informações sobre o perfil sociodemográfico dessa população, além de identificar atividades produtivas desenvolvidas no domicílio e peridomicílio e os possíveis fatores de risco para a saúde dos trabalhadores (Silva, Dias e Ribeiro, 2011).

Sobre o trabalho dos ACSs, os enfermeiros enfatizaram que as ações de ST podem ser desenvolvidas pelos agentes, sugerindo que os próprios enfermeiros, como responsáveis pela supervisão dos ACSs, podem apoiar as ações de ST executadas pelos agentes.

Os enfermeiros consideraram que a atuação dos ACSs no campo da ST requer habilidades e conhecimentos específicos, o que implica uma qualificação sólida e permanente. Nesse sentido, para uma formação em Visat, a maioria dos entrevistados constatou que devem ser realizadas ações de educação permanente em vez de capacitações pontuais, pois estas, em sua maioria, não produzem o efeito esperado.

Os enfermeiros discutiram também o papel e a contribuição do Cerest e do Núcleo de Apoio à Saúde da Família (NASF) no sentido de apoiar os ACSs na execução das ações de ST. Os entrevistados compreendem que essas estruturas são responsáveis pelas capacitações em ST e são instâncias que podem realizar o matriciamento em Visat.

Porém, apesar de o Cerest ter sido caracterizado pelos informantes dessa etapa como responsável pelas capacitações, ele é visto por alguns enfermeiros como um setor distante da $\mathrm{AB}$, o que sinaliza para a necessidade de o Cerest e da atenção básica trabalharem pela construção ou ampliação desse espaço de discussão. Chiavegatto (2010) enfatiza que o Cerest deve buscar uma aproximação com a rede básica, que parece carente dessa relação de forma mais sistematizada, formalizada e ampliada. Assegura que é preciso também fortalecer ações intersetoriais.

Com relação ao NASF, a maioria dos enfermeiros identificou que o núcleo é atuante e já desenvolve ações com as eSF, a exemplo de atendimento em grupo e atendimento individual, atendimento individual compartilhado, educação em saúde, entre outras. Para os enfermeiros, o NASF tem uma relação consolidada com os ACSs, embora seja necessário incluir o olhar para as ações de ST.

\section{Os ACSs e a construção da proposta pedagógica}

Participaram dessa etapa da pesquisa 23 ACSs. Foram realizados três grupos focais: um com os agentes da zona urbana, outro com os da zona rural e outro com os do distrito de Lagoa das Flores, região intermediária entre as zonas 
urbana e rural. A divisão em zonas urbana e rural foi utilizada para definir os grupos focais tendo em vista que as regiões podem apresentar demandas distintas para as ações em ST, já que as atividades produtivas e as condições de trabalho se organizam de modos diferentes. Dos ACSs que participaram do estudo, $83 \%$ eram do sexo feminino. A predominância de mulheres desempenhando a função também foi relatada no estudo de Silva (2009).

A idade variou entre 25 e 59 anos, com maioria entre 30 e 35 anos, o que caracterizou uma predominância de adultos jovens exercendo a função de ACS. Faixa etária semelhante foi encontrada também em outros estudos como o de Silva (2009). No que tange à escolaridade, observou-se que $52 \%$ dos ACSs concluíram o segundo grau; $13 \%$ estavam cursando o ensino superior; e $13 \%$ tinham ensino superior completo.

Ao analisar o tempo de trabalho como ACS, observou-se uma predominância (74\% dos agentes) entre dez e vinte, sinalizando baixa rotatividade desse trabalhador na atividade. Identificou-se que $61 \%$ dos ACSs já participaram de alguma capacitação em ST promovida pelo Cerest em momentos de capacitação dos profissionais da rede básica. Durante a discussão no grupo focal, verificouse que esses agentes apresentaram mais segurança e clareza em seus relatos.

As questões de ST estão no cotidiano de pessoas, famílias, comunidades e grupos sociais, exercendo relevante influência na qualidade de vida, no adoecer e no morrer dos segmentos sociais, o que foi amplamente discutido pelos agentes - demonstrando a importância de se conhecerem o território, a população trabalhadora, as principais atividades produtivas e as principais situações de risco e perigo para a saúde dos trabalhadores.

Os agentes discutiram também as ações que realizavam para ofertar cuidado à saúde dos trabalhadores, a exemplo de ações educativas, orientações sobre os riscos e perigos relacionados ao trabalho e os encaminhamentos necessários.

A maioria dos ACSs conhecia os dispositivos da saúde que podem fornecer auxílio às ações de ST. Eles relataram as ações do NASF - nenhuma relacionada à saúde do trabalhador - com mais conhecimento e proximidade, ao contrário do Cerest, que apesar de ser reconhecido como o setor específico para referência nas ações de ST, está distante da atenção básica, o que também foi relatado pelos enfermeiros.

Outra situação abordada na discussão diz respeito ao tipo de orientação fornecida pelos ACSs aos usuários trabalhadores. Os agentes utilizam os saberes do senso comum e de sua própria experiência e se ressentem da falta de instrumentos, tecnologias e saberes para apoiar as diversas dimensões esperadas de seu trabalho. Resultado semelhante foi encontrado por Silva (2009) em seu estudo. Silva (2001) destaca o uso pelos agentes do saber 'emprestado' dos profissionais da equipe, como médicos e enfermeiros. Reitera que, quando tais saberes são insuficientes, os agentes levam os próprios profissionais à casa do usuário do serviço ou o caso do usuário à unidade de saúde. 
Observou-se durante a discussão que a realidade do trabalho dos ACSs coloca-os diante de demandas das mais diversas. Eles destacaram a necessidade de conhecer mais o tema das relações trabalho-saúde-doença de modo a facilitar sua atuação. Expressaram que nas visitas domiciliares encontram trabalhadores que desenvolvem seu trabalho em diversos ambientes, possivelmente em situações de risco - o que significa para os agentes a necessidade de conhecimentos e habilidades para orientar o trabalhador sobre a existência dos riscos e a importância da sua participação no processo de intervenção e transformação do trabalho, assim como no que diz respeito às medidas necessárias para proteção e prevenção.

Os agentes relataram dificuldade em orientar a comunidade sobre a adoção de medidas de prevenção, pois não se sentiam preparados para a identificação de alguns riscos relacionados ao trabalho e não conheciam as doenças e os meios e instrumentos que poderiam ser usados para proteção do trabalhador. Os agentes com mais tempo de serviço conheciam o Cerest e sabiam que poderiam encaminhar o usuário caso necessário. Os ACSs mais novos relataram não conhecer esse serviço da ST. "Muitas vezes até falta de conhecimento de quem pode nos dar um auxílio. O único conhecido que a gente ainda tem na saúde do trabalhador é só o Cerest, né. / A gente nem sabe onde é nada. / A gente não se sente preparado. Falta conhecimento".

Observou-se nos relatos a necessidade de qualificação para as ações de cuidado à saúde dos usuários trabalhadores, haja vista que os agentes compreendiam a relação trabalho-saúde-doença. Nesse sentido, o ACS pode orientar o usuário sobre o caminho a ser percorrido na rede, informando sobre o fluxo para atenção integral. As visitas domiciliares do ACS favorecem a identificação e a superação de obstáculos para uma atenção ágil e resolutiva.

Uma necessidade identificada na fala dos ACSs é a construção de um fluxo estruturado para o cuidado à ST. Esse fluxo pode solucionar os problemas relacionados ao desconhecimento dos profissionais de saúde acerca das questões que abarcam a área, incluindo o conhecimento da função do Cerest, dos órgãos e instrumentos de apoio à ST e do caminho a ser percorrido pelo usuário trabalhador.

Os ACSs identificaram como outra dificuldade o acesso a grandes empresas. Um ponto a ser considerado é a complexidade dos seus processos de trabalho. Apresentam-se a seguir algumas falas dos ACSs extraídas do estudo que deu origem a este artigo.

Nós orienta [sic] as pessoas que procura, entendeu? Porque chega em qualquer fábrica dessa pra ver se você tem acesso de entrar lá pra ver o funcionário trabalhar. Não tem. 
Você não pode chegar lá e falar com o cara que tá trabalhando de uma forma certa ou errada, né? (...) Mas a gente, seria interessante a gente chegar pra dona de casa, pro trabalhador e falar: Ó, a forma que o senhor poderia melhorar sua forma de trabalhar seria assim.

Assim, é necessário sensibilizar o olhar dos ACSs para eles identificarem trabalhadores mais vulneráveis, os trabalhos domiciliados, supermercados, açougues, farmácias, salões de beleza, agricultura de subsistência etc., assinalando a presença de riscos relacionados a processos produtivos mais simples. Nesses casos, a produção do cuidado aos trabalhadores poderia ser mais efetiva, haja vista um acesso mais facilitado dos ACSs.

Um dos pontos do roteiro do grupo focal buscou explorar o conceito de Visat. O conceito presente nas falas dos sujeitos aproxima-se de uma ação que objetiva descobrir falhas na execução das atividades nos locais de trabalho, que vão desde as fábricas às lavouras, também compreendida como prática educativa no sentido de orientar os trabalhadores a adotarem medidas de prevenção.

Segundo Daldon e Lancman (2013), o papel da Visat não é apenas fiscalizador, mas também educativo, sensibilizador e mobilizador de ações transformadoras que precisam ocorrer em parceria com os trabalhadores e em uma abordagem articulada intersetorialmente. Suas ações não se voltam apenas para o trabalhador, mas também para os gestores das empresas, que devem ser sensibilizados para a importância de tais mudanças. Para essas autoras, a Visat inclui componentes essenciais, como a informação e suas diretrizes de ação; a intervenção em processos, condições e ambientes de trabalho; a educação, a comunicação e a promoção da saúde; a participação do controle social e dos diferentes atores comprometidos no processo.

O conceito de Visat suscitou uma discussão sobre a reponsabilidade da ação. Ao classificarem a Visat como uma ação de fiscalização, atribuíram a ela um alto nível de complexidade que não pode ser executado por eles. Alguns ACSs relataram desconhecer quem deve realizar a Visat; outros, os agentes com maior tempo de trabalho e que já foram capacitados em ST, conferiram essa responsabilidade ao Cerest.

A PNST entende que a ST é uma área transversal e compreende a inserção das ações de Visat numa perspectiva intra e intersetorial. Nesse sentido, a Visat deve estar presente em todos os pontos da rede de atenção, o que não quer dizer que a operacionalização da dinâmica processual das ações não seja complexa. Entretanto, a Visat deve se pautar na perspectiva de uma ação estruturante e essencial ao modelo de atenção integral em ST (Brasil, 2012).

Assim, ao se analisarem as falas de alguns ACSs quando eles afirmam não ser capazes de realizar uma ação de Visat, não se espera que a $\mathrm{AB}$ nem 
os agentes executem o ciclo completo dessa ação. Mas a expectativa é que o nível primário da atenção, em especial os ACSs, possa cumprir a tarefa inicial e essencial de identificar situações-problema, muitas vezes complexas e que podem se ampliar caso sejam dadas condições e suporte a essas equipes. No município de Vitória da Conquista, quem executa as ações de Visat é a equipe do Cerest. Em algumas situações, as ações acontecem em parceria com a vigilância sanitária (Vitória da Conquista, 2014).

Ao discutir a qualificação em Visat e as metodologias de formação, foi possível identificar a demanda dos ACSs por capacitação e suporte técnico para o desenvolvimento de ações de Visat. No entendimento dos agentes, a capacitação em Visat objetiva qualificá-los para o desenvolvimento de ações como identificar a população trabalhadora e o perfil produtivo de sua área de atuação, situações geradoras de riscos à saúde dos trabalhadores e orientações e ações educativas. Durante a discussão no grupo focal, os sujeitos compreenderam que essa demanda poderia ser suprida por meio da implementação da proposta construída no estudo aqui apresentado, que será mostrada mais adiante. O suporte técnico para o desenvolvimento das ações de Visat demanda o efetivo envolvimento intrassetorial do Cerest e do NASF desempenhando as funções de apoio matricial, conforme pode se observar nas falas seguintes:

Eu enquanto (sic) trabalhadora pra tá vigiando, fazendo a vigilância em saúde do trabalhador, eu precisaria de uma capacitação mais detalhada, mais aprofundada pra gente, porque a gente já faz o basicão. Só por cima mesmo.

Os grupos focais permitiram identificar que os agentes não têm preparação prévia específica para lidar com as questões que envolvem as atividades de Visat, o que os faz recorrerem aos saberes do senso comum ou saberes adquiridos em experiências anteriores para orientarem o encaminhamento dos problemas.

Outra questão levantada pelos agentes diz respeito às diferenças territoriais e ao modelo de organização dos processos de trabalho. Os grupos de Lagoa das Flores e da zona rural apresentaram como demanda inserir na capacitação informações específicas sobre o perfil produtivo e riscos relacionados ao trabalho da sua área de abrangência, bem como as medidas de prevenção e orientações para tais casos. Nesse sentido, a proposta de capacitação em Visat deve respeitar as diferenças locorregionais, pois é evidente que as necessidades apresentadas em determinado território estarão atreladas ao tipo de trabalho desenvolvido por sua população e em seu território de abrangência.

As falas dos sujeitos elencaram diversos conteúdos para a proposta pedagógica de qualificação em Visat: relações trabalho-saúde-doença; conceitos 
básicos do campo da saúde do trabalhador e da vigilância em saúde do trabalhador; legislação trabalhista; legislação previdenciária e sanitária; Sistema de Agravos de Notificação; e atribuições dos ACSs na Visat.

Para Franch (2008), os profissionais que atuam na AB devem ser formados de modo a atingir pelo menos quatro objetivos em ST: reconhecer o impacto do trabalho e das condições em que ele é desenvolvido sobre a saúde geral dos trabalhadores, identificando fatores de risco; conhecer aspectos legais, administrativos e institucionais básicos relacionados à saúde dos trabalhadores; deter conhecimentos quanto às doenças relacionadas ao trabalho, segundo riscos específicos e atividades laborais desenvolvidas; e assistir os trabalhadores e prover informações básicas a eles quanto a aspectos clínicos, preventivos e administrativos, considerando condições individuais e fatores de risco associados.

Diante do conteúdo que foi elencado pelos ACSs, avalia-se que esses objetivos em ST poderão ser alcançados com a proposta pedagógica de qualificação em Visat construída no estudo aqui apresentado.

Sobre a metodologia de formação em Visat, os sujeitos comentaram a participação em processos de capacitação pouco interativos, curtos, com excesso de informação para ser absorvida em pouco tempo e salas muito cheias. Eles foram unânimes em afirmar que desejavam uma qualificação participativa, dinâmica, que associasse conteúdos teóricos a experiências práticas e com carga horária mais extensa:

Uma capacitação interativa, dinâmica; / Eu também acho que a gente deveria tá conhecendo setores (...) fazer uma visita; / Trazer relatos de caso pra gente entender melhor. Porque tudo isso aí vai facilitar pra gente entender e até mesmo passar pra comunidade (...)

Seria bom uma capacitação de 40 horas e só com os ACSs. Colocar pra participar mesmo, entendeu? E se esse caso, por exemplo, for lá na sua área, você faz o quê? Aí depois vir explicando a forma correta de como faria.

Os depoimentos expõem o desejo dos sujeitos de participarem de algo que ultrapasse as barreiras da capacitação e se constitua num processo de educação permanente. De acordo com a PNEPS, as bases definidoras dos processos formativos das equipes devem ser a problematização do processo de trabalho e as necessidades de saúde dos indivíduos e coletividades, o que também foi expresso pelos entrevistados.

Nesse sentido, o enfoque da educação permanente representa uma importante mudança na concepção e nas práticas de capacitação dos trabalhadores dos serviços. Supõe inverter a lógica do processo, incorporando o ensino e o aprendizado à vida cotidiana dos serviços e às práticas sociais e de trabalho, 
no contexto real em que ocorrem. A educação permanente propõe a modificação substancial das estratégias educativas, a partir da prática como fonte de conhecimento, problematizando o próprio fazer e situando os trabalhadores como atores reflexivos da prática e construtores do conhecimento e de alternativas de ação, em vez de meros receptores.

\section{Uma pedagogia emancipadora na capacitação de agentes comunitários de saúde}

Ao dar voz ao sujeito, cabe uma pergunta: quem é o portador da autoridade que concede a voz ao outro? No processo de EPS, pressupõe-se que a autoridade seja o portador de um acúmulo de conhecimentos que, em sua missão, dispõe-se a transmitir o conteúdo necessário para que o outro possa exercer a sua própria missão. Ocorre que suas missões são muito distintas no cenário operacional exigido para o funcionamento do sistema. O agir operativo do outro não é o mesmo do portador da autoridade de ensinar. Um ensina - ação de ensinar em si -, outro aprende - ação de aprender para mudar seu agir operativo. Há nessa interação uma equação que não fecha. Para fechar a equação, é necessário que a autoridade seja transferida ao outro - o que aprende. O mecanismo da alteridade passa a ser um constructo pedagógico do processo ensino-aprendizagem. Transferir ao outro a autoridade do que deve aprender e do que precisa saber para o seu agir operativo cotidiano é uma prática emancipatória dos sujeitos envolvidos nesse contexto pedagógico. Assim, a proposta foi desenvolvida dando não só a voz ao outro, mas também a autoridade do que lhe deve ser propiciado. A consciência intencionada ao mundo é o desafio a ser enfrentado (e construído) na formulação pedagógica proposta (Freire, 2013).

Conferir protagonismo ao ACS na construção de seu próprio aprender, em matéria de saúde do trabalhador inclusive, guarda coerência com o protagonismo do trabalhador no desenvolvimento de políticas e ações no campo da saúde do trabalhador (Vasconcellos, Almeida e Guedes, 2010).

Apresentamos a seguir a proposta pedagógica construída a partir das falas que compõem o estudo, dos saberes, inquietações e desejos dos sujeitos da pesquisa: os agentes comunitários de saúde.

Inicialmente procedeu-se à leitura flutuante das falas. Em seguida, iniciouse a constituição do corpus do trabalho, buscando atender à exaustividade, à representatividade, à homogeneidade e à pertinência. Na segunda etapa, ocorreu a exploração do material num sentido classificatório, buscando alcançar o núcleo de compreensão do texto e formulação das categorias com base na redução do texto às palavras e expressões significativas. Em seguida, os dados foram classificados e agregados. A terceira etapa consistiu no tratamento dos 
resultados e interpretação, inter-relacionando os dados com o marco teórico desenhado inicialmente, resultando na produção do Quadro 1.

\section{Quadro 1}

Proposta pedagógica de qualificação em Visat a partir das falas dos ACSs

\begin{tabular}{|cc|}
\hline Discurso dos sujeitos Conteúdos & \\
\hline Conceitos & \\
\hline
\end{tabular}

(...) A parte teórica, né? De dizer tudo pra gente. O que é saúde do trabalhador, o que vem a ser realmente vigilância em saúde do trabalhador (...) (RBSS). ${ }^{1}$

Tem também aquele trabalhador que não é carteira assinada. A gente precisa saber como fazer pra orientar nesse caso (SSSP).

Então a gente precisaria saber direito o que é o Sinan, o que é mesmo a vigilância em saúde do trabalhador, e qual é o nosso papel enquanto ACS (GPQ). ${ }^{1}$

Acho que falando das doenças adquiridas. Quais são os direitos em lei do trabalhador, qual é a obrigação do... do dono da empresa. Orientar sobre INSS. Seja lá que trabalho for que aquele trabalhador exerça (CA). ${ }^{1}$

(...) todos os temas que envolva a saúde do trabalhador. Como a gente pode orientar no caso do INSS, no caso de acidente de trabalho, dos riscos do trabalho (RAR).

Quem é o trabalhador?

Trabalho e trabalhador / Trabalho formal e informal. Processo de trabalho / Trabalho domiciliado. A saúde do trabalhador no SUS.

Risco e perigo / Influência do trabalho na saúde e no adoecimento

Relação trabalho-saúde-doença na área de abrangência Mapeamento de atividades produtivas.

Identificação da população trabalhadora.

Condições de saúde dos trabalhadores.

Doenças e agravos relacionados ao trabalho mais comuns.

O que é vigilância em saúde do trabalhador?

Legislação relacionada à Visat / Visat na atenção básica. Atribuições do ACS em Visat e cuidado à ST.

O que é o Cerest / Parceiros nas ações de Visat / Sinan.

\section{Direitos trabalhistas e previdenciários}

Tipos de segurado.

Benefícios previdenciários.

Direitos do trabalhador doméstico.

\section{Metodologia}

Uma capacitação interativa, dinâmica. Porque muitas vezes a capacitação ela se torna muito monótona, só falando. E tem pessoas que a voz dá sono (RAR).

Quando é mais dinâmico, mais participativo, que tem pessoas pra dar informação, tiver atividades que isso aí acaba até mesmo enriquecendo. Porque a gente absorve mais do que a pessoa, tendo só uma pessoa falando e a gente ouvindo (CA).

Eu também acho que a gente deveria tá conhecendo setores. Estar levando a gente pra ficar conhecendo, fazer uma visita (KCFS).
Estudos de caso que envolvam trabalho rural, trabalho domiciliar, trabalho em fábricas de cimento, bloco, reciclagem, calçados, entre outros.

Visita técnica ao Cerest e demais dispositivos da saúde que oferecem suporte à saúde do trabalhador.

Assistir a filmes como llha das Flores e Tempos modernos. Dramatizações / Trabalho em grupo.

Elaborar um diagnóstico situacional em saúde do trabalhador da área de abrangência. 


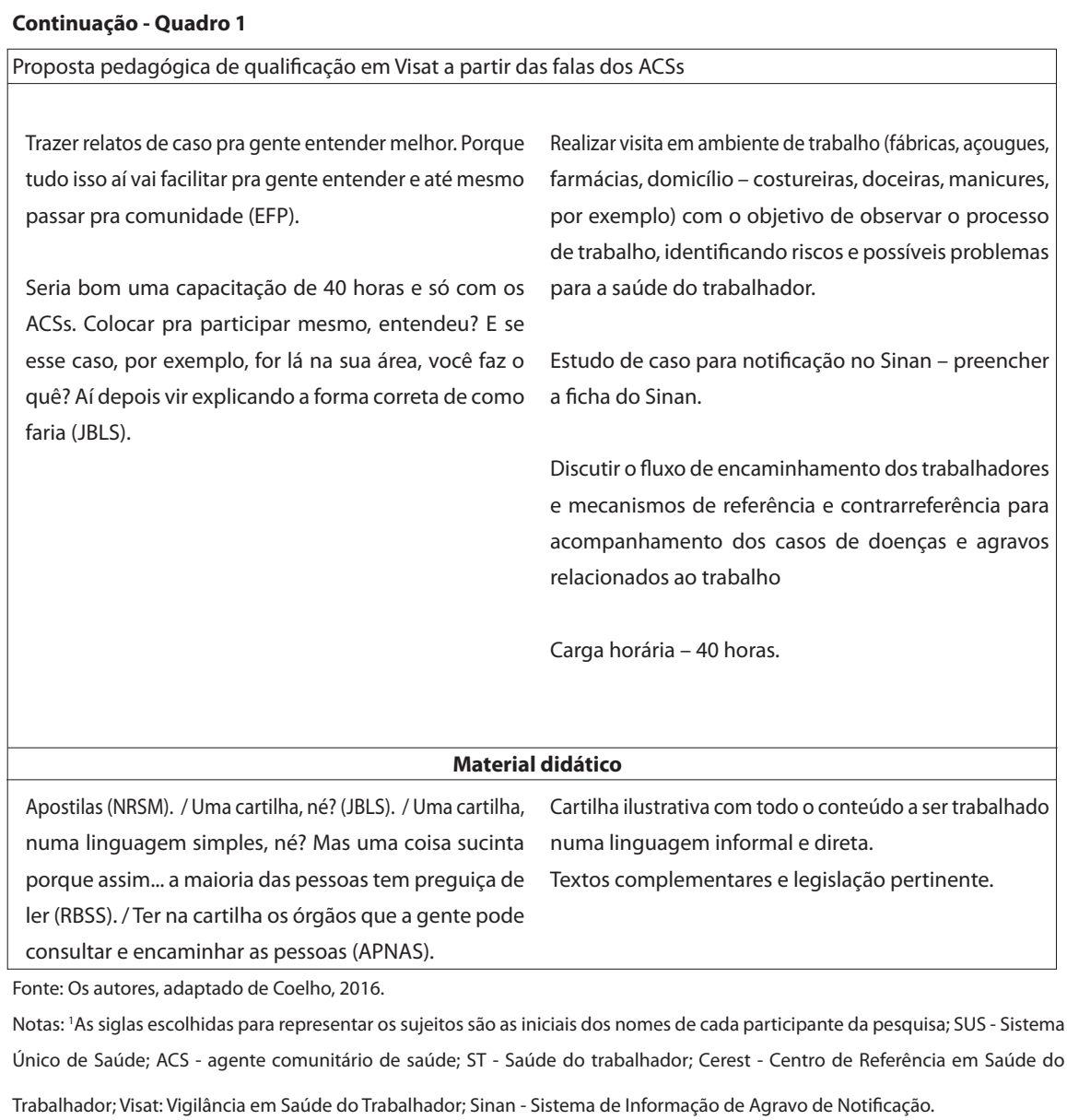

\section{Considerações finais}

Embora a capacitação dos ACSs em ST seja encarada como um desafio, os enfermeiros consideraram que os agentes podem desenvolver ações no campo da vigilância em saúde do trabalhador, como mapear e identificar o perfil da população trabalhadora da sua área de abrangência, reconhecer situações de risco à saúde dos trabalhadores e realizar ações educativas, desde que sejam capacitados para tal. Nesse sentido, a capacitação deve ocorrer na perspectiva da educação permanente, já que esta propõe uma mudança das estratégias de educação e das práticas de capacitação dos trabalhadores. Investir na capacitação dos profissionais da $\mathrm{AB}$ é indispensável para refletir criticamente sobre o trabalho.

A discussão nos grupos focais instrumentalizou a construção de uma proposta pedagógica de qualificação em Visat para os ACSs e se constituiu numa experiência ímpar de valorização do trabalho dos agentes, possibilitando o diálogo com esses trabalhadores para identificação de conceitos, elementos e 
saberes necessários à construção de processos de capacitação que facilitem o desenvolvimento de ações de cuidado aos usuários trabalhadores.

Não obstante em formulações pedagógicas desse tipo seja esperado um discurso similar dos ACSs nas diversas regiões do país, no que tange às suas necessidades de ensino-aprendizagem cabem duas observações. Uma diz respeito ao conteúdo enunciado pelos sujeitos. Transformar suas percepções em pacote didático aplicável a qualquer capacitação, ao se considerar que o discurso terá poucas variações em experiências similares, é uma atitude que desconsidera o protagonismo dos sujeitos na autoria de seu percurso de cidadão e profissional de saúde. Portanto, presume-se que a reprodutibilidade desse método seja direcionada apenas à sua aplicação e não aos resultados com ela obtidos.

Outra observação remete às peculiaridades das realidades locais, em suas perspectivas cultural, epidemiológica e espacial. Nesse caso, por se estar no eixo doutrinário e organizacional do SUS, com uma similaridade do discurso do agir operativo, o cenário que marca a vida dos ACSs e dos usuários é distinto em cada localidade. Como num teatro, mantém-se o texto, mas muda-se a cena dos diálogos - o que modifica a forma como o público e os personagens em cena vivenciam suas questões, desejos e necessidades.

Assim, espera-se que o estudo aqui apresentado possa subsidiar a capacitação dos ACSs em Visat nos moldes da EPS, oportunizando aos agentes o exercício de cidadania e autonomia, de modo a contribuir para a consolidação das ações de saúde do trabalhador no SUS.

\section{Colaboradores}

Todos os autores contribuíram igualmente para a produção e revisão do artigo e declaram que não há conflitos de interesses. 
Resumen Este artículo presenta una síntesis de observaciones desarrolladas en una pesquisa que tuvo como objetivo elaborar un proyecto pedagógico para calificación de los agentes comunitarios de salud en Vigilancia en salud del trabajador a partir de la percepción de los propios sujetos. Tratase de un estudio realizado en 2016 en Vitória da Conquista, Brasil, que utilizó cualitativo que utiliza el marco teórico de la técnica de investigación-acción y grupo de enfoque para abordar el tema. El primer paso de los resultados expone la visión de los enfermeros en relación con la calificación de los agentes de salud en vigilancia en salud del trabajador y en el segundo se describe la participación y el conocimiento de los agentes comunitarios de salud en la construcción de la propuesta de formación pedagógica. Las enfermeras sugirieron que la formación en vigilancia en salud del trabajador fuera construida en base a los supuestos de la educación permanente y expresaron su interés en participar en este proceso educativo. Hubo unanimidad de los participantes de los agentes sobre la necesidad de formación y recomendarán materiales de contenido, metodología y enseñanza para la construcción de la propuesta pedagógica. Por supuesto, expresaron, aun, el deseo de participar en un proceso educativo que sea capaz de superar las barreras de la formación como un verdadero proceso de educación permanente en salud.

Palabras clave vigilancia de la salud de los trabajadores; agente comunitario de salud; educación permanente en salud.

\section{Notas}

${ }^{1}$ Prefeitura de Vitória da Conquista, Centro de Referência em Saúde do Trabalhador, Bahia, Brasil. <jamillygusmao@hotmail.com>

Correspondência: Rua Cláudia Botelho, 775, Candeias. Mirante Vitória, Bloco 10, apto 204. CEP 45028-190.Vitória da Conquista, BA, Brasil.

${ }^{2}$ Fundação Oswaldo Cruz, Escola Nacional de Saúde Pública Sergio Arouca, Departamento de Direitos Humanos, Saúde e Diversidade Cultural, Rio de Janeiro, RJ, Brasil. <elfadel@globo.com>

3 Universidade Federal de Minas Gerais, Programa de Pós-Graduação em Saúde Pública; Fundação Oswaldo Cruz, Escola Nacional de Saúde Pública Sergio Arouca, Mestrado Profissional em Saúde Pública e Ambiente, Rio de Janeiro, RJ, Brasil. <bethdias@gmail.com>

${ }^{4}$ A Rede Nacional de Atenção Integral à Saúde do Trabalhador (Renast) compreende uma rede nacional de informações e práticas de saúde, organizada com o propósito de implementar ações assistenciais, de vigilância, prevenção e promoção da saúde na perspectiva da ST. Os Centros de Referência em Saúde do Trabalhador (Cerests) devem apoiar investigações de maior complexidade, subsidiar a formulação de políticas públicas, fortalecer a articulação entre a atenção básica, de média e alta complexidade para identificar e atender acidentes e agravos relacionados ao trabalho (Brasil, 2012). 


\section{Referências}

BARDIN, Laurence. Análise de conteúdo. São Paulo: Edições 70, 2011, 229p. 2009.

BRASIL. Portaria n. 198, de 13 de fevereiro de 2004. Institui a Política Nacional de Educação Permanente em Saúde como Estratégia do Sistema Único de Saúde para a formação e o desenvolvimento de trabalhadores para o setor e dá outras providências. Diário Oficial da República Federativa do Brasil, Poder Executivo, Brasília, 13 fev. 2004. Seção 1, p. 37-41

BRASIL. Portaria n. 1.996, de 20 de agosto de 2007. Dispõe sobre as diretrizes para a implementação da Política Nacional de Educação Permanente em Saúde e dá outras providências. Diário Oficial da República Federativa do Brasil, Poder Executivo, Brasília, 20 ago. 2007. Seção 1, p.34-38.

BRASIL. Portaria n. 3.252, de 22 de dezembro de 2009. Aprova as diretrizes para execução e financiamento das ações de Vigilância em Saúde pela União, Estados, Distrito Federal e Municípios e dá outras providências. Diário Oficial da República Federativa do Brasil, Poder Executivo, Brasília, 23 de dez. 2009. Seção 1, p. 65-69.

BRASIL. Portaria n. 1.823, de 23 de agosto de 2012. Institui a Política Nacional de Saúde do Trabalhador e da Trabalhadora. Diário Oficial da República Federativa do Brasil, Poder Executivo, Brasília, 23 ago. 2012. Seção 1, p. 46-51.

BRASIL. Portaria n. 2.488 de 21 de outubro de 2011. Aprova a Política Nacional de Atenção Básica, estabelecendo a revisão de diretrizes e normas para a organização da Atenção Básica, para a Estratégia Saúde da Família (ESF) e o Programa de Agentes Comunitários de Saúde (PACS). Diário Oficial da República Federativa do Brasil, Poder Executivo, Brasília, 24 out. 2011. Seção 1.

CECCIM, Ricardo B.; FERLA, Alcindo A. Educação permanente em saúde. In: PEREIRA, Isabel B.; LIMA, Júlio C. F. (orgs.). Dicionário da educação profissional em saúde. Rio de Janeiro: EPSJV, 2006. p. 107-112.
CHIAVEGATTO, Claudia V. Percepção dos profissionais de nível superior da atenção primária quanto ao desenvolvimento de ações de saúde do trabalhador no SUS em Minas Gerais. 2010. 128f. Dissertação (Mestrado em Saúde Pública) - Universidade Federal de Minas Gerais, Belo Horizonte, 2010.

COELHO, Jamilly G. Elaboração de um projeto pedagógico para qualificação dos agentes comunitários de saúde em vigilância à saúde do trabalhador: a construção compartilhada com os próprios sujeitos. 161f. Dissertação (Mestrado em Saúde Pública) - Escola Nacional de Saúde Pública Sergio, Fundação Oswaldo Cruz, Vitória da Conquista, 2016.

DALDON, Maria T. B.; LANCMAN, Selma. Vigilância em saúde do trabalhador: rumos e incertezas. Revista Brasileira de Saúde Ocupacional, São Paulo, v. 38, n. 127, p. 92-106, 2013.

DIAS, Elizabeth C.; HOEFEL, Maria G. O desafio de implementar as ações de saúde do trabalhador no SUS: a estratégia da Renast. Ciência \& Saúde Coletiva, Rio de Janeiro, v. 10, n. 4, p. 817-828, dez. 2005.

DIAS, Elizabeth C.; RIGOTTO, Raquel M.; AUGUSTO, Lia G. S. Saúde ambiental e saúde do trabalhador na atenção primária à saúde, no SUS: oportunidades e desafios. Ciência \& Saúde Coletiva, Rio de Janeiro, v. 14, n. 6, p. 2.061-2.070, 2009.

DIAS, Elizabeth C.; SILVA, Thais L. Contribuições da atenção primária em saúde para a implementação da Política Nacional de Saúde e Segurança no Trabalho (PNSST). Revista Brasileira de Saúde Ocupacional, São Paulo, v. 38, n. 127, p. 31-43, 2013.

DIAS, Elizabeth C.; SILVA, Thais L.; ALMEIDA, Magda H. C. Desafios para a construção cotidiana da vigilância em saúde ambiental e em saúde do trabalhador na atenção primária à saúde. Cadernos Saúde Coletiva, Rio de Janeiro, v. 20, n. 1, p. 15-24, 2012. 
FRANCH, Imma C. La atención primaria de salud, un agente clave de la salud laboral. Atención Primaria, Barcelona, v. 40, n. 1, p. 7-14, 2008.

FREIRE, Paulo. Educação e mudança. Tradução de Moacir Gadotti e Lillian Lopes Martins. 30. ed. Rio de Janeiro: Paz \& Terra, 2007.

FREIRE, Paulo. Pedagogia da autonomia: saberes necessários à prática educativa. 47. ed. Rio de Janeiro: Paz e Terra. 2013. 143p.

FREIRE, Paulo. Pedagogia do oprimido. 58. ed. Rio de Janeiro: Paz e Terra, 2014. 253p.

GOMES, Karine O. et al. O agente comunitário de saúde e a consolidação do Sistema Único de Saúde: reflexões contemporâneas. Physis: Revista de Saúde Coletiva, Rio de Janeiro, v. 20, n. 4, p. 1.143-1.164, 2010.

MACHADO, Jorge M. H. Vigilância em saúde do trabalhador: conceitos e pressupostos. In: MOURA CORRÊA, Maria J.; PINHEIRO, Tarcísio M. M.; MERLO, Álvaro R. C. (orgs.). Vigilância em saúde do trabalhador no Sistema Único de Saúde: teorias e práticas. Belo Horizonte: Coopmed, 2013. p. 23-34.

QUINTANA, Pedro B.; ROSCHKE, Maria A. C.; RIBEIRO, Eliana C. O. Educación permanente, proceso de trabajo y calidad de servicio en salud. In: HADDAD-Q, Jorge. ROSCHKE, Maria A. C.; DAVINI, Maria C. Educación permanente de personal de salud. Washington, D.C.: OPS, 1994. p. 33-61.

ROVERE, Mario R. Gestion de la educacion permanente: una relectura desde una perspectiva estratégica. Educación Médica y Salud. Washington, D.C.: OPS, v. 27, n. 4, p. 489-515, 1993.

SILVA, Joana A. O agente comunitário de saúde do Projeto Qualis: agente institucional ou agente de comunidade? 2001. 231f. Tese (Doutorado em Saúde Pública) - Universidade de São Paulo, São Paulo, 2001.

SILVA, Thais L. Contribuição ao processo de capacitação dos agentes comunitários de saúde para o desenvolvimento de ações de saúde do trabalhador. 2009. 146f. Dissertação (Mestrado em Saúde Pública e Meio Ambiente) - Escola Nacional de Saúde Pública Sergio Arouca, Fundação Oswaldo Cruz, Rio de Janeiro, 2009.

SILVA, Thais L.; DIAS, Elizabeth C. Contribuições da atenção primária em saúde para a implementação da Política Nacional de Saúde e Segurança no Trabalho (PNSST). Revista Brasileira de Saúde Ocupacional, São Paulo, v. 38, n. 127, p. 31-43, 2013.

SILVA, Thais L; DIAS, Elizabeth C.; RIBEIRO, Eliana C. O. Saberes e práticas do agente comunitário de saúde na atenção à saúde do trabalhador. Interface: Comunicação, Saúde e Educação, Botucatu, v. 15, n. 38, p. 859-870, 2011.

THIOLLENT, Michel. Metodologia da pesquisaação. 18. ed. São Paulo: Cortez, 2011.

VASCONCELLOS, Luiz C. F.; ALMEIDA, Carmem V. B.; GUEDES, Dimitri T. Vigilância em saúde do trabalhador: passos para uma pedagogia. Trabalho, Educação e Saúde, Rio de Janeiro, v. 7, n. 3, p. 445-462, 2010.

VASCONCELLOS, Luiz C. F.; OLIVEIRA, Maria H. B. O sujeito sanitário na perspectiva do direito. In: OLIVEIRA, Maria H. B. et al. (orgs.). Direito e saúde: cidadania e ética na construção de sujeitos sanitários. Maceió: Edufal. p. 27-52, 2013.

VIEIRA, Meire C. F. Contribuições para o desenvolvimento de ações de vigilância da saúde do trabalhador domiciliar, na atenção primária à saúde, no município de Juiz de Fora. 62f. Trabalho de Conclusão de Curso (Especialização em Saúde Pública) - Fundação Oswaldo Cruz, Rio de Janeiro, 2009.

VITÓRIA DA CONQUISTA. Centro de Referência em Saúde do Trabalhador. Secretaria de Saúde. Relatório anual de gestão. Prefeitura Municipal de Vitória da Conquista, 2014.

Recebido em 20/09/2016. Aprovado em 11/08/2017. 